\title{
Review
}

\section{Ebola from emergence to epidemic: the virus and the disease, global preparedness and perspectives}

\author{
Kuldeep Dhama ${ }^{1}$, Yashpal Singh Malik², Satya Veer Singh Malik ${ }^{3}$, Raj Kumar Singh ${ }^{4}$ \\ ${ }^{1}$ Division of Pathology, Indian Veterinary Research Institute (IVRI), Izatnagar, Uttar Pradesh, India \\ ${ }^{2}$ Division of Biological Standardization, Indian Veterinary Research Institute (IVRI), Izatnagar, Uttar Pradesh, India \\ ${ }^{3}$ Division of Veterinary Public Health, Indian Veterinary Research Institute (IVRI), Izatnagar, Uttar Pradesh, India \\ ${ }^{4}$ Indian Veterinary Research Institute (IVRI), Izatnagar, Uttar Pradesh, India
}

All authors contributed equally to this paper.

\begin{abstract}
Humans constantly encounter threats from many infectious, zoonotic, and devastating pathogens. Outbreaks of severe acute respiratory syndrome (SARS), bird flu, and swine flu posing pandemic threats have compelled health agencies to follow global preparedness for combating the emerging deadly pathogens. The outbreak in West Africa of highly contagious Ebola viral disease (EVD) that started in Guinea in December 2013, assumed global proportions to become the largest outbreak of EVD and the most prominent international health concern. With fatality rates of nearly 50\%-90\%, it has claimed, as of 11 April 2015, 10,619 human lives out of a total of 25,626 cases reported worldwide. Ebola virus (EBOV), a member of Filoviridae family, is associated with severe, often lethal, hemorrhagic fever disease in humans and animals. The animal hosts, including non-human primates and reservoir hosts (fruit bats), play a significant role in transmission and maintenance of EBOV in nature. Although no approved vaccine for the prevention of EVD currently exists, disease control can be greatly enhanced by timely laboratory confirmation through blood tests using enzyme-linked immunosorbent assay (ELISA) and reverse transcription polymerase chain reaction (RT-PCR). Adherence to strict sanitary and hygienic measures, monitoring and surveillance of EBOV, as well as quarantine checks on international trade, transport, and visitors from affected countries are mandatory to prevent and control the spread of EVD. This review describes the salient properties of EBOV and the development of novel diagnostics, vaccines, and control strategies for this emerging disease of high public health concern and international emergency.
\end{abstract}

Key words: Ebola virus; epidemiology; transmission; diagnosis; prevention; control.

J Infect Dev Ctries 2015; 9(5):441-455. doi:10.3855/jidc.6197

(Received 04 November 2014 - Accepted 18 April 2015)

Copyright $\odot 2015$ Dhama et al. This is an open-access article distributed under the Creative Commons Attribution License, which permits unrestricted use, distribution, and reproduction in any medium, provided the original work is properly cited.

\section{Introduction}

Ebola virus disease (EVD) caused by the Ebola virus (EBOV), which was identified almost four decades ago in 1976, is an emerging and re-emerging zoonosis. This highly contagious and virulent disease in humans which ends the life within a short span of time [1-3], still poses a major threat to the world community, especially in the West African countries Guinea, Sierra Leone, Mali, Senegal, and Liberia, where it caused the biggest outbreak in the history of Ebola in June 2014, prior to its emanation for a global spread (Figure 1). The EBOV leads to lethal hemorrhagic fever in human and non-human primates $[4,5]$ with a high case fatality rate in humans that varies according to virus serotype and that can go up to $90 \%$. In view of its imminent lethality in general and highly fatal nature for humans in particular, the EBOV has been categorized under class A agents of dangerous biological weapons requiring highly specialized laboratories equipped with appropriate biosafety standards including biosafety containment level 4 (BSL-4) for handling the virus and biological materials suspected to be contaminated with it. In the yearlong ongoing outbreak, as of 11 April, 2015, this virus has claimed 10,619 human lives, with a total of 25,626 affected and laboratory confirmed cases worldwide [6]. The EVD initially develops with flulike symptoms, stomach pain, diarrhea and/or vomiting associated with unexplained bleeding or characteristic hemorrhages on account of damaged blood vessels, finally leading to high mortality and rapid virus spread from infected to healthy persons through direct contact or infected materials. At higher risk of acquiring infection are the health workers, family members, and others who come in close contact with the people who are sick due to EBOV infection. 
The EVD leads to massive damage in families as well as communities, and the infection can only be controlled by strictly following the recommended protective measures in clinics as well as hospitals, community gatherings, homes, or other infected places $[4,7,8]$. In the West African countries, the traditional burial practice where the body of the deceased is washed by their relatives has been seen fuelling the spread of EVD because the dead body is a rich source of the virus. It is necessary to adopt safe medical burial practices of infected subjects and to make people aware of its importance in order to minimize the spread of EBOV through contact.

Currently, EBOV has largely been limited to the African countries; however, trade globalization, population increase, and rapid international transport connectivity potentiated its incidences in other countries in the world through incidental transmission that may assume pandemic proportion. Emergence of EVD cases in the United States of America, Spain, and the United Kingdom, though sporadic, must be seen as the most appropriate time to further consolidate on global preparedness with rapid response teams involving staff trained in animal health, wildlife, and medical sciences, so as to effectively and quickly tackle this devastating pathogen capable of rapidly spreading across national boundaries. The present review describes the salient properties and features of the EBOV as well as its epidemiology, transmission, pathology, and the recent advances in the area of diagnosis, vaccination, prevention, treatment, and control of EVD.

\section{Etiology}

Ebola virus (EBOV) is a negative-stranded RNA virus belonging to the genus Ebolavirus of the family Filoviridae, order Mononegavirales. The Marburgvirus and Cuevavirus are other two members of this family. Marburg and Ebola viruses are filamentous in shape, causing hemorrhagic fever in humans and have high case fatality rates. EBOV was isolated for the first time in 1976 during the Ebola hemorrhagic fever (EHF) outbreaks occurring in the Democratic Republic of the Congo (then Zaire) as well as Sudan. The name Ebola was derived from the name of a river in Zaire valley from where this deadly virus was reported for the first time [7]. The virus was initially named Ebola-like virus, which was changed to Ebola virus in 2002. The genus Ebolavirus contains five species: Zaire Ebola virus (ZEBOV), Sudan Ebola virus (SEBOV), Tai Forest Ebola virus (TEBOV), Reston Ebola virus (REBOV), and Bundibugyo Ebola
Figure 1. Distribution and the locations of disease outbreaks caused by Ebola virus (EBOV). The colored areas indicate countries where cases of EBOV have been documented.

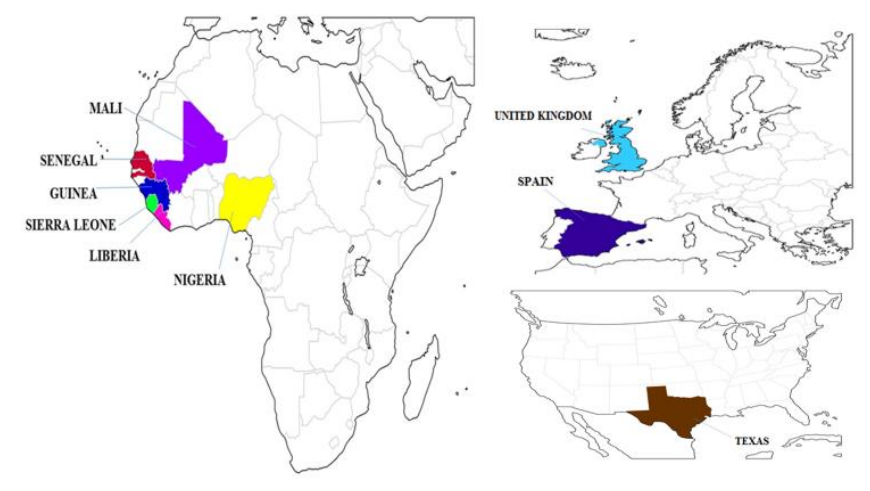

virus (BEBOV) [9]. It is noteworthy that only two species, SEBOV and ZEBOV, caused lethal human outbreaks, with the latter one being more devastating and destructive in nature, causing lethality in more than $90 \%$ cases $[3,10]$. The ZEBOV was earlier reported only from the central part of Africa; however, this strain of EBOV has been incriminated as the cause of recent outbreaks of EVD in Guinea, Liberia, Nigeria, Senegal, and Sierra Leone (in West Africa) [11].

The 19-kb-long genome of EBOV has seven open reading frames (ORFs) that encode structural proteins such as nucleoprotein (NP), envelope glycoprotein (eGP), and matrix proteins (VP24 and VP40). The major non-structural proteins are VP30 and VP35, and viral polymerase. The ribonucleoprotein complex has different role in pathogenesis; like VP35, it acts as an antagonist of interferon. VP40 is a matrix protein involved in budding and the release of virus from host cell. Similarly, another protein, VP24, which is situated in the membrane, inhibits the signalling of the interferon [12]. The glycoprotein ORF of EBOV provides two set of gene products, namely 60 to 70 $\mathrm{kDa}$ soluble glycoprotein (sGP) and a full-length 150 to $170 \mathrm{kDa}$ glycoprotein (GP) that is located into the viral membrane, through transcriptional editing. In humans, the rates of genetic changes occurring in EBOV may be 100 times slower than that in influenza A viruses; however, the divergence of EBOV was reported to have taken place several thousand years ago $[13,14]$. The EBOV envelope glycoprotein (eGP) plays multiple functions in viral pathogenesis as it aids in virus attachment and entry to cells, causes cell rounding, down-regulates host surface proteins, enhances virus assembly and budding, and also mediates widespread inflammation, cytotoxicity, and 
cellular damage, while secretary glycoprotein (sGP) is secreted by the virus infected host cells [15-17].

\section{Epidemiology and epidemiological timeline}

Ever since the beginning of the first Ebola epidemic in 1976, a number of suspected and laboratory-confirmed cases of EVD have been increasing. This deadly virus, which claimed 6,458 deaths out of 12,299 cases reported in Africa until 2012 with an overall mortality rate of $52.5 \%$ during its four decades of appearance [2,3,18,19], has further widened its death trap, claiming 10,619 lives out of 25,626 suspected and confirmed cases reported globally during the current Ebola outbreak alone from December 2013 until April 11, 2015 [6]. The first global epidemic of Ebola in 2014 was declared to be a public health emergency of international concern by World Health Organization; it is the largest outbreak in Ebola history and the first massive outbreak in West Africa, and thereby, created a seemingly out-of-control situation [8,20,21]. The EVD outbreak in the West African countries Guinea, Sierra Leone, Liberia, Senegal, and Nigeria is due to the most perilous ZEBOV [3]. Historically, the year 1976 marked the victimization of a 44-year-old school teacher named Mabalo Lokela in a place called Yambuku in northern Democratic Republic of the Congo by the EVD due to ZEBOV [22]. A number of other cases were reported in the subsequent years and almost all of them centered either on the Yambuku mission hospital or the persons who had close contact with the infected cases. In the same year when ZEBOV was identified, a new species from Sudan was reported for the first time and named SEBOV [23]. During the first outbreaks of EVD that occurred in 1976 in Congo (Zaire) and Sudan, the mortality rates were observed to be $71.59 \%$ (Figure 2). Thereafter, two more new species were
Figure 2. Timeline of Ebola virus disease (EVD) outbreaks with deaths and total cases reported since 1976 (first record of Ebola).

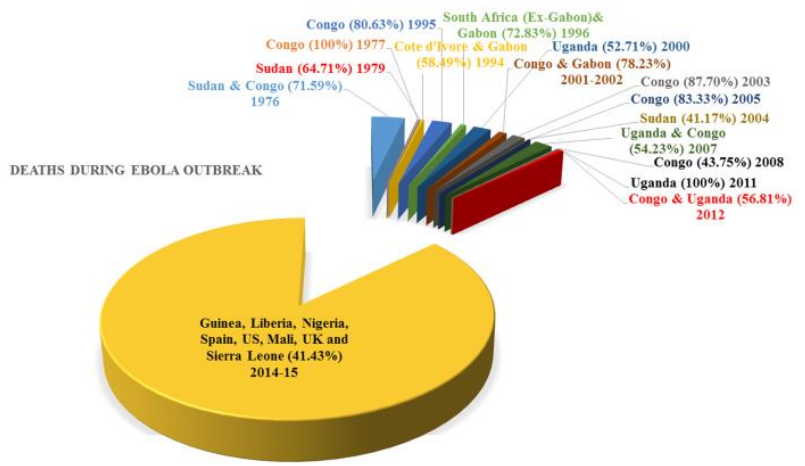

identified as Côte d'Ivoire Ebola virus (CIEBOV) in 1994 from the Ivory Coast, Bundibugyo Ebola virus (BEBOV) in 2007 from Uganda [2,18]. There have also been reports of infection due to the BEBOV. The first EBOV reported outside of Africa and named Reston Ebola virus (REBOV), was from Virginia, United States of America, and this was later also reported from Philippines and Italy [24]. Tai Forest Ebola virus (TEBOV) was first reported from Ivory Coast in 1994.

Ebola has caused devastating outbreaks with fatality rates of $25 \%-90 \%$ in Africa and Asia. The timeline of EBOV outbreaks in African countries and the mortality rates ranging from $50 \%$ to $100 \%$ are summarized in Figure 2, with country-wise details for Sudan and Congo $(71.59 \%, 1976)$, Congo (100\%, $1977 ; 80.63 \%$, 995; 87.70\%, 2003; 83.33\%, 2005; $43.75 \%, 2008)$, Sudan $(64.71 \%, 1979 ; 41.17 \%, 2004)$, Ivory Coast and Gabon $(58.49 \%, 1994)$, South Africa (Ex-Gabon) and Gabon (72.83\%, 1996); Uganda (52.71\%, 2000; Uganda, 100\%, 2011); Congo and Gabon (78.23\%, 2001-2002); Uganda and Congo

Table 1. Current scenario of the number of EBOV cases and death/fatality rates during recent EVD outbreaks.

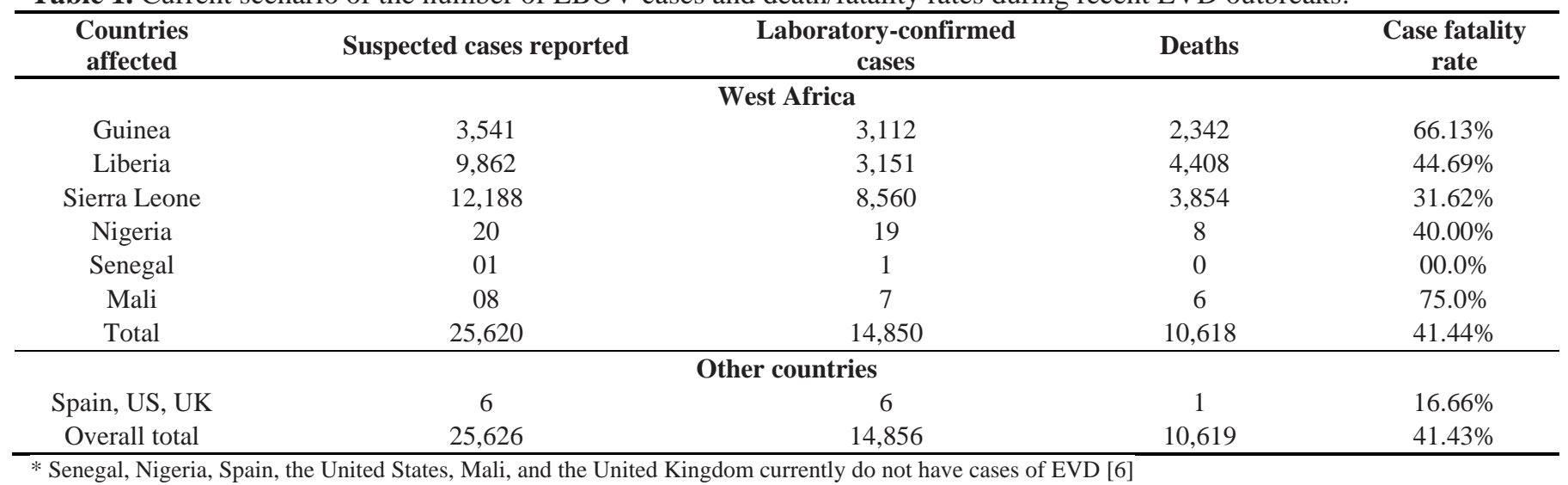


(54.23\%, 2007; 56.81\%, 2012); Guinea, Liberia, Nigeria, Sierra Leone, Mali and Senegal (31.62\%75\%, 2014-2015) [2,6,18,25,26]. Recently, EVD incidences have also been reported from other countries viz., The United States of America (1 death out of 4 laboratory confirmed cases); Spain and the United Kingdom (one laboratory-confirmed case each but with no fatality). A brief overview of the number of EBOV suspected and laboratory-confirmed cases along with deaths and fatality rates during recent EVD outbreaks in West African and other few countries is presented in Table 1.

\section{Host range}

ZEBOV is known to cause severe and lethal disease in non-human primates. The virus also produces fatal hemorrhagic fever in cynomolgus and rhesus macaques (Macaca fascicularis and Macaca rhesus), baboons (Papio hamadryas), and African green monkeys (Cercopithecus aethiops). Experimental inoculation of ZEBOV-infected material from humans into guinea pigs resulted in development of a febrile non-lethal disease. Sequential passage of splenic homogenates containing ZEBOV from animal to animal resulted in development of a progressive enhancement of virulence and quickly attained uniform lethality in laboratory animals. Inoculation of ZEBOV by intraperitoneal or intracerebral routes resulted in lethal infection in newborn mice and adult SCID BALB/c mice. However, only newborn mice are sensitive to EBOV infection, whereas adult mice are resistant. Recent studies also indicated that EBOV infection can be transmitted to dogs as well as pigs. In certain regions of Africa, scavenging dogs, while searching for food, have been known to eat animals infected with EBOV. Such dogs remain asymptomatic; however, a survey conducted in 2005 revealed over $30 \%$ seroprevalence for the EBOV infection in dogs, but there were no clinical outward manifestations; hence, a clear picture regarding the transmission of EBOV from dogs could not be inferred [27,28]. Pigs may tend to develop disease that is symptomatic in nature. Reports regarding natural infection of pigs by REBOV have been documented in the Philippines. Transmission of virus from pigs to human via respiratory and direct contact with the body fluids of pigs has also been reported in 2008 [28]. Moreover, the transmission of the virus can occur from pigs to primates (non-human). The detection of EBOV in pigs also raises concerns regarding animal health and food safety, and that whether EVD may be considered a transboundary animal disease [5].
Figure 3. The major routes of Ebola virus (EBOV) transmission and maintenance between humans, bats, and non-human primates.

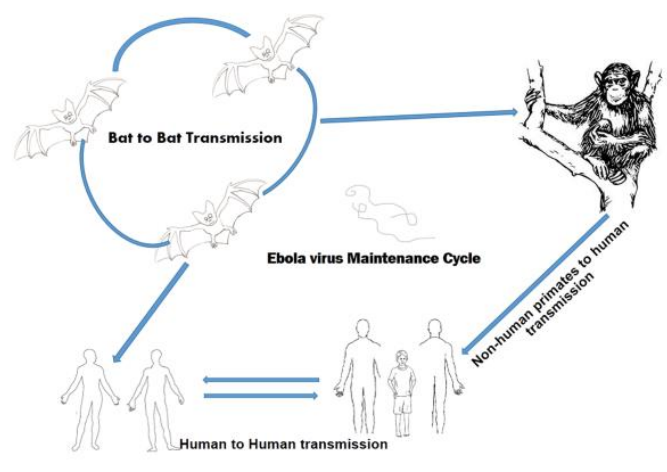

EVD has an emerging and re-emerging pattern, and therefore, scientists hypothesize the involvement of reservoir hosts that can maintain the EBOV. Several evidence-based scientific works have highlighted that fruit bats, especially those belonging to the three species Epomops franqueti, Hypsignathus monstrosus, and Myonycteris torquata serve as a potential reservoir host for EBOV [29]. Recently, the presence of antibodies against EBOV in bats from Bangladesh supported the theory that they may be natural reservoirs of this deadly virus [15]. However, the involvement of intermediate hosts in transmission of EBOV to the end host is yet to be elucidated. The role of non-human primates as reservoirs has been ruled out. Unlike animals, humans are generally susceptible to EBOV without any gender or age group variation; however, its status as natural reservoir still remains unclear. EBOV RNA could be extracted from certain rodents inhabiting the central part of Africa, but it was insufficient evidence to implicate them as reservoirs. An increase in the mortality amongst gorillas and chimpanzees infected with ZEBOV has been linked with the human outbreaks, and contact with dead nonhuman primates, and hunting and eating fruit bats has been suggested to be the predisposing factors or primary sources of transmission of EBOV to humans (Figure 3) [2,18].

\section{Transmission and spread}

The major mode of transmission of EBOV infection in human beings is by direct contact with body secretions/fluids (saliva, urine, feces, blood, semen) or tissue/organ of infected or sick persons, as well as organ transplantation from such cases. The main routes of EBOV infection are through mucous membrane, conjunctiva, small skin breaks, infected needles or syringes, unhygienic practices such as 
unsterile burial customs, including cleansing of infected corpse. Humans can also get this zoonotic infection by handling already-infected non-human primates or their body secretions/fluids [5]. Bats can carry more than 100 different viruses including Ebola, rabies, and SARS without becoming sick themselves. The threat of EBOV to humans from bats comes en route to the tainted bush meat, which has also been implicated in the EVD outbreaks. The virus passes from bats to antelopes, squirrels, porcupines, and monkeys, which have long held pride of place on menus in West and Central Africa. The danger of contracting Ebola lies in exposure to infected blood in the killing and preparation of animals. Mucosal transmission of EBOV infection has been proven in non-human primates, but it can also occur in humans. Aerosol dissemination of EBOV has been associated with the disease development in non-human primates, which may raise an, albeit remote, possibility of airborne infection of EBOV in humans [15]. However, in this context, Dr. Tom Frieden, Director of CDC, USA clarified that in the history of all viruses, scientists have yet to see a virus mutating so that it becomes airborne to spread via droplets like influenza, where the dried viral particles can travel long distances in the air. In fact, Ebola cannot survive without a fluid vehicle such as saliva, sweat, blood, feces, or vomit, and the liquid cannot travel as far as the dry particles can go in the air. According to CDC, surface transmission may be possible, but is not considered a high risk. Much needs to be revealed regarding the myths surrounding EBOV, such as its endemic nature to certain parts of Africa, reservoir hosts, and emerging and re-emerging pattern. Studies on the zoonotic niche of EVD in Africa also indicate that the dynamics of human-to-human transmission in contemporary outbreaks may be very different as compared to the past [30].

\section{Pathogenesis}

Entry of EBOV through the skin or mucosa paves way for its entry to target monocytes, macrophages, and dendritic cells, which play pivotal roles in the dissemination of the virus as it spreads from the initial infection site via these cells to regional lymph nodes, probably through the lymphatic system, and to the liver and spleen through the blood. The host immune system and vascular bed is directly affected by EBOV entering macrophages and dendritic cells through pinocytosis to reach the endosomal vesicles (Figure 4). EBOV-primed host macrophages and monocytes release the inflammatory cytokines in very high levels in blood stream, which destroy the normal tissues and microcirculation as well as cause extensive damage to the endothelial vessels, thereby leading to massive blood loss, which is the major feature of EBOV infection [15]. The coagulation mechanism inside the blood vessels is also activated to cause intravascular coagulation. Death can occur either due to coagulation or due to severe blood loss [16]. Thrombocytopenia, consumption of clotting factors, and increased concentrations of fibrin degradation products are major mechanisms responsible for coagulopathy during EBOV infections. The virus-infected monocytes and macrophages release tissue factors, which induces the development of coagulation irregularities. Rapid reduction in plasma concentrations of the natural anticoagulant protein $\mathrm{C}$ is also responsible for coagulation. Profound capillary leakage, renal failure, and disseminated intravascular coagulation are observed in persons suffering with severe EVD [31,32]. Unlike normal circumstances wherein antibodies developed against any infectious agent help to get rid of that particular pathogen from body, EBOV utilizes these antibodies along with the complement factor $\mathrm{C} 1$ to cause severe cell damage, thereby exaggerating its pathogenesis. The antibodies attach to EBOV and subsequently their Fc region gets attached to the $\mathrm{C} 1 \mathrm{q}$ complement region, which in turn aids in their attachment to the target receptors on macrophages and dendritic cells, and thus the

Figure 4. A schematic representation of Ebola virus (EBOV) pathogenesis in humans.

On entry of the virus through the skin/mucosal layer, EBOV targets dendritic cells (DCs) and macrophages. Infected cells seed the virus and replication occurs. Virus-encoded proteins suppress the host protein synthesis machinery and host innate defence. The virus releases through budding mediated through VP40 protein of EBOV. There is also an outburst of cytokines, which further damages the host cells and endothelial cells, leading to massive blood loss and death due to hypovolemic shock.

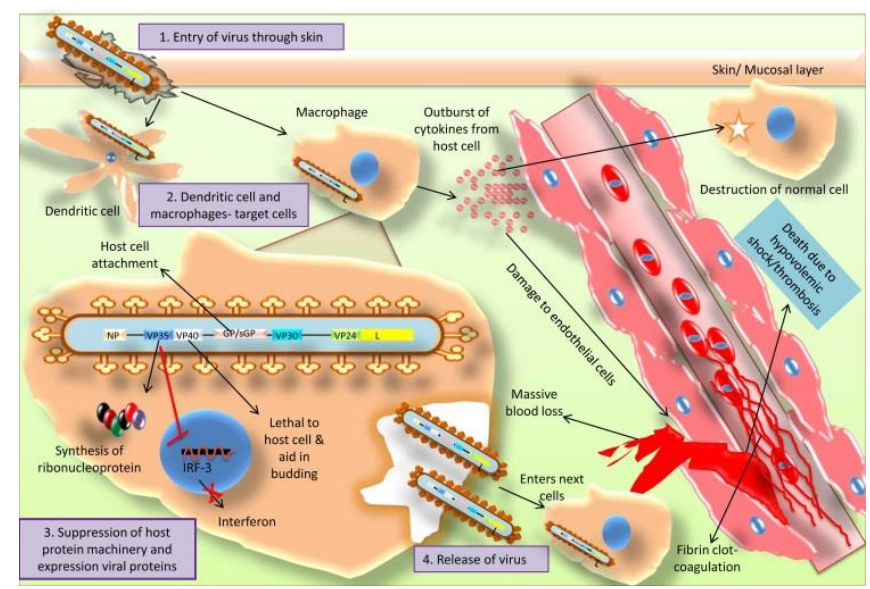


adherence of EBOV to the host cells occurs. By utilizing antibody-enhanced infection pathways, the EBOV reaches various organs to cause extensive damage.

Pathological lesions include necrosis of various organs, including liver, ovaries, testes, and kidneys; hemorrhages in mucosa; and biochemical disturbances such as marked aminotransferase level, noticeable lymphocytopenia, and prominent thrombocytopenia. The liver reveals numerous small necrotic foci moderately infiltrated with inflammatory cells and randomly distributed in the hepatic lobules. The most prominent change in hepatocytes is the formation of numerous multinucleated syncytia of hepatic cells. The spleen shows marked congestion and extensive areas of fibrinoid and hemorrhagic necrosis of the red pulp. Fibrinoid necrotic areas mixed with numerous red blood cells are more apparent in the marginal zones surrounding lymphoid follicles. The cytoplasm of numerous splenic macrophages contain large, amorphous, acidophilic material that is similar to the intracytoplasmic viral inclusion bodies. The gastric and intestinal mucosae exhibit mild diffuse infiltration of the lamina propria and the submucosa by mononuclear inflammatory cells. Diffuse inflammation is associated with several delimited pyogranulomatous lesions of the intestinal wall, with a large infiltration of activated macrophages mixed with neutrophilic and many eosinophilic granulocytes. Lung parenchyma reveals blood stasis, intra-alveolar terminal edema, and mild chronic emphysema [33].

\section{Cellular replication cycle of EBOV}

During EBOV infection, the VP35 protein of virus regulates two important functions. Firstly, it is crucial for production of the ribonucleoprotein (RNP) complex, which is necessary for replication of virus and transcription [34]. Secondly, VP35 inhibits the type I interferon (IFN) signalling of the host cell system $[35,36]$ by preventing the phosphorylation of interferon regulatory factor (IRF)-3, which is a main element of the immediate early signalling mechanisms that activate the antiviral cellular response. The VP35 protein of EBOV, therefore, helps in facilitating viral pathogenesis by (i) antagonizing the interferon produced during EBOV infection [39]; (ii) obstructing the commencement of host cellular IFN (IFN- $\alpha / \beta)$ response by virtue of blocking the activation of constitutively expressed transcription factor IRF-3; and (iii) preventing the dsRNA-mediated antiviral gene induction with the help of viral nucleic acid, so as to check the expression of anti-viral proteins in the infected cells $[35,37]$. The matrix protein VP40 has the ability to bud from host cells and form a membraneencompassed virus-like particle (VLP) without need of other viral proteins [38-40]. The envelope GP and some of the viral proteins interacting with the immune mechanisms may play crucial role in acquiring higher virulence by this lethal virus [41].

Around the world, research activities are being pursued for understanding the precise molecular mechanisms of EBOV infection [42]. Recently, the role of proteins encoded by microRNAs (miRNAs) in the molecular pathogenesis of this virus has been elucidated, wherein adhesion-related molecules tissue factor pathway inhibitor (TFPI) dystroglycan 1 (DAG1) and the caspase 8 and FADD-like apoptosis regulator (CFLAR) were found to be downregulated significantly in EBOV GP-expressing human umbilical vein endothelial cells (HUVECs). The most crucial findings of pioneer nature emanating from such work are expected to pave a way forward for the development of ideal diagnostics, vaccines, and drugs that are urgently needed to effectively tackle this international public health emergency.

\section{Immunobiology of Ebola virus infection}

EBOV multiplies rapidly and overcomes protein synthesis machinery and immune defence mechanisms of the cells. The immune system responds to EBOV infection through both innate and adaptive arms. The mononuclear phagocytes such as monocytes and macrophages, and other cells such as endothelial cells and hepatocytes, are the major targets of EBOV infection [43]. The pathogenesis involves both the host and virus-encoded proteins, and it leads to the release of higher amount of inflammatory cytokines, namely IFN- $\gamma$, IFN- $\alpha$, interleukin-2 (IL-2), tumor necrosis factor alpha (TNF- $\alpha$ ) and IL-10, which are responsible for EBOV hemorrhages and fatality [44]. The antibody can be detectable as early as day 6 after infection in experimentally infected animals and can persist for less than 90 days. The IgG response is less rapid; however, it persisted for more than 400 days in animals who survived infection and persisted for $\sim 10$ years after infection in human sera [45]. Detectable levels of antibodies against EBOV glycoproteins have been easily diagnosed in the serum of recovered cases; however, such sera failed to constantly offer protection from the disease or to show inhibition of virus replication in cell culture. It was noteworthy that passive antibody administration in animal models could prevent the appearance of clinical signs but with no change in overall survival, indicating that in a 
natural infection of EBOV, the protective immunity is not solely provided by the antibodies, and that cellular immunity may also play a significant role in disease resistance. Currently, any case in which a person acquired Ebola more than once is not known to scientists, indicating that disease survivors might have developed a lifelong immunity, similar to monkeys, who are known to have it in such cases.

\section{Clinical symptoms and lesions}

Usually, the symptoms of EBOV infection begin suddenly, similar to influenza in the initial stages, and include nausea, vomiting, abdominal pain, diarrhea, loss of appetite, muscular pain, headache, fatigue, and lymph node enlargement $[5,15]$. The incubation period (IP) may fluctuate from 4 to 10 days, sometimes up to 21 days, followed by a sudden rise in temperature which is usually above $38^{\circ} \mathrm{C}$. Humans and non-human primates affected with EBOV show severe hemorrhages and pyrexia. Less-common symptoms include sore throat, pain in the chest, hiccups, breathing shortness, and trouble swallowing. Poor coagulation of blood during venipuncture or bruises are noticed, and there may be traces of blood in the urine. Bleeding may be restricted only to the gastrointestinal tract, leading to blood in the feces. The skin reveals a maculopapular rash in approximately $50 \%$ of cases. There is involvement of circulatory symptoms, such as clotting of the blood. There have been reports of bleeding from sites of mucous membranes (gastrointestinal tract, nose, vagina, gums) in $40 \%-50 \%$ of the cases. The bleeding phase starts typically within a period of 5-7 days after the development of first symptoms. There may be bleeding in internal as well as subcutaneous areas, and it is manifested as reddening of the eyes along with blood in the vomitus, cough, or the feces. In rare occasions, there is heavy bleeding with usual confinement to the gastrointestinal tract. There may be creation of petechiae as well as purpura, ecchymoses, and hematomas due to skin bleeding, especially around sites of needle injection. In the lack of any recovery of the infected person, there death due to multiple organ dysfunction syndrome and heavy blood shedding can occur within 7-16 days (usually between 8 and 9 days) after the onset of symptoms [41,46]. In the final stages, patients tend to vomit, their respiration rate increases and body temperature decreases, which results in grave prognosis. Persons who escape death will have problems such as joint pain, swelling of various organs, and orchitis.

\section{EBOV diagnosis}

The diagnosis of EVD is done on the basis of clinical symptoms, detection of antigen/virus and the antibodies [15,47]. Antigen/virus detection can be adopted for infection at early stages while antibody detection can be done at the late stage of infection.

\section{Clinical symptoms}

The clinical symptoms seen during the acute cases of EVD are confounding. In most cases, the diagnosis of EBOV infection is made clinically, once the symptoms of EVD develop. In the early stages of infection, it is difficult to diagnose the EVD clinically, as there are non-specific early symptoms that resemble with those of several other diseases. Under these circumstances, timely laboratory confirmation of this deadly viral infection becomes essential for the control of EVD outbreaks. Blood parameters such as low platelet count and white blood cell count combined with elevated level of hepatic enzymes are indicative of EVD [48].

\section{Antigen/virus detection}

Antigen detection methods are mainly useful in the early phase of the infection, when the virus load is higher in the system. Virus isolation is the important key for confirmatory diagnosis, which can be done in Vero and Vero E6 cell lines. Plaque assay serves as the assay of choice to detect the infectious viruses in a cell culture system. The major disadvantage of the isolation of virus in cell culture is the need of BSL-4 facility to handle the sample and organism since EBOV is highly lethal. The absolute diagnosis needs tests using state-of-art diagnostic arrays including reverse transcription-polymerase chain reaction (RTPCR) [49,50], IgG- and IgM-based antigen-capture enzyme-linked immunosorbent assay (ELISA) [45], serum neutralization tests, electron microscopy, and immunohistochemical tests demonstrating the virus in tissue sections [51]. The utility of antigen-capture ELISA has been tested with satisfactory results for detecting Ebola virus in patients' serum, plasma, and whole blood. Blood tests for diagnosis of EBOV infections are ELISA and RT-PCR. However, RTPCR assay could detect Ebola virus in samples collected during the very early course of infection. The sensitivity of EBOV detection can further be improved with SYBR Green [52] or TaqMan-based real-time quantitative RT-PCR assays [53]. A multiplex realtime fluorescence quantitative PCR has also been developed to detect the Ebola and Marburg viruses [54]. Though RT-PCR is more effective in detecting 
EBOV, the disadvantage of this technique is the need for sophisticated instruments that cannot be afforded by most parts of Africa where the disease is reported the most [47]. For the rapid and simple detection of Ebola virus, an efficient reverse-transcription loopmediated isothermal amplification (LAMP) method with high specificity and rapidity has been reported to have been developed, targeting the trailer region of the viral genome [55]. The developed RT-LAMP assay has been reported to be fast that it could detect the virus within 26 minutes. Due to its various advantages of simplicity, rapidity, high sensitivity, efficiency, and specificity, the LAMP test could be of high diagnostic value in the field or laboratories for testing EBOV in EVD outbreak-affected areas. Sequence analysis of the variable region of the EBOV glycoprotein has also been found to be very informative. Because Ebola is a zoonotic and highly contagious pathogen, handling and processing of samples from suspected EVD cases should be done in BSL-4 facilities.

The search is on for an ideal diagnostic test that is capable of immediately identifying the patients needing quarantine and discriminating them from the cases that do not need to be quarantined. Several versions of point-of-care rapid diagnostic tests are under development; a few of the diagnostic kits developed recently for EBOV detection are presented in Table 2. Corgenix, a US company, has perfected its prototype similar to a pregnancy test-style slip of paper that reveals a dark red line within 15 minutes when exposed to a drop of Ebola-infected blood. The test would need only a pin prick to get the sample, similar to diabetes testing, and ideally would be a very rapid and cost-effective diagnostic, and therefore would be likely to have applications far beyond West Africa [56]. French scientists have also devised a fasttrack test for Ebola; a European pharmaceutical company, Veda Lab, is turning it into a user-friendly kit called Ebola eZYSCREEN, similar to a home pregnancy test. The test would be able to diagnose a patient with suspected Ebola in less than 15 minutes. It works by monoclonal antibodies reacting to the presence of virus in a tiny sample, which can be a drop of blood, plasma, or urine.

\section{Antibody detection}

Testing of persons can also be done for antibodies after recovery takes place. Detection of antibodies can be done in the late symptomatic phase, when the patients are in recovery time. Antibody detection tests mostly involve detection of IgG or IgM antibodies by an ELISA test [45,51]. Positive results in antibody detection tests reveal EVD, but a negative result will not indicate the patient to be free of EBOV because antibodies will be developed only in the later stage of the disease; due to high lethality of the disease, the chances of a person escaping the early phase of infection are lower. Other useful serological or antibody detection tests for EVD include indirect immunofluorescence test and western blot [51]. Crossreactivity with other pathogens is also a common disadvantage in most of the serological assays.

\section{Prevention and control}

The United Nations (UN) made a rapid response to the current Ebola epidemic by creating a mission named as UN Mission for Ebola Emergency Response (UNMEER) for effectively tackling this public health emergency. The mission pooled and oriented vast resources of the UN agencies for reinforcing the WHO's technical expertise and experience in managing Ebola disease outbreaks. However, in the absence of an effective vaccine in hand, the only way left with global health agencies is to keep the spread of EBOV under check by strengthening and strictly implementing appropriate prevention and control

Table 2. Diagnostic kits developed recently for Ebola virus (EBOV) detection

\begin{tabular}{cllll}
\hline No. & \multicolumn{1}{c}{ Kit name } & Type of the test & Company name & Company country \\
\hline 1 & $\begin{array}{l}\text { RealStar Filovirus Screen RT-PCR Kit } \\
1.0\end{array}$ & Antigen detection: RT- PCR & Altona Diagnostics & Germany \\
& $\begin{array}{l}\text { AccuPower EBOV Quantitative RT- } \\
2\end{array}$ & $\begin{array}{l}\text { Antigen detection: RT- PCR } \\
\text { PCR Kit (EBO-1111A) }\end{array}$ & Bioneer & Korea \\
3 & LIPSGENE SEBOV/ZEBOV Kit & Antigen detection: PCR kit & Lipsdiag & Germany \\
4 & - & Antigen detection: LAMP & Lucigen & USA \\
5 & LightMix Modular Ebola virus Zaire & Antigen detection: PCR & Tib-molbiol & Germany \\
6 & $\begin{array}{l}\text { Rapid Response Ebola Virus Test } \\
\text { Cassette }\end{array}$ & $\begin{array}{l}\text { Antigen detection: chromatographic } \\
\text { immunoassay }\end{array}$ & BTNX Inc. & Canada \\
7 & ReEBOV Antigen Rapid Test Kit & $\begin{array}{l}\text { Antigen detection: } \\
\text { Immunochromatographic dipstick }\end{array}$ & Corgenix & USA \\
\hline
\end{tabular}


measures, including regular monitoring, tracking, and surveillance of the circulating viruses, infected persons, potential suspects, and people inhabiting or visiting epidemic affected areas, especially African countries [19].

The local and global strategies framed to combat the Ebola epidemic had involved state-of-the art early warning systems for tracking global movement of people travelling through outbreak-affected countries, rapid screening of the patients and suspects, rapid medical care to patients, safe disposal of dead persons and their discharges through dedicated health personnel, and disaster management planning and implementing agencies operating at national and international levels. Biomedical waste and used items such as sheets, garments, gowns, cleaning supplies, or anything that came into contact with the patient or their bodily fluids must be sterilized before they are removed from the hospital or cleaning site. Approved guidelines of the WHO/CDC should be followed for complete sterilization of used equipment, hygienic and safe collection of blood samples, disinfection of infected areas, and proper disposal of patients who died of EBOV infection. Sterilization can be achieved in an autoclave or by incineration, as both kill the virus. Hospitals without these facilities should triplepack the waste in water tight containers before it is carted away for final disposal. Fecal waste can be flushed down the toilet, provided the sewer system is designed to deactivate infectious agents. EBOVinfected individuals must be identified early and isolated. Treatment of the infected persons should be done in an isolated area, preferably in specially designed isolation wards with facilities for proper disposal of the potentially infected materials and discharges emanating from such premises, as these can act as a nidus of infection. The disposal/burial of infected dead bodies in a strictly hygienic and proper manner as well as compliance with good sanitary, phytosanitary, and hygienic measures must be ensured in order to check the spread of the virus from victims of the EBOV infection to healthy persons or clean places, and to disrupt the virus transmission chain.

In international travel and trade settings, strict surveillance and follow-up of the disease suspects (probably infected), infected, quarantined, and convalescent (previously treated and now recovering) subjects, especially those who inhabit or visit places hit by Ebola outbreak, remains the key to preventing the spread of infection to countries that are naive to EBOV infection. It can be achieved by keeping high vigil at airports and ports as well as other entry checkpoints for monitoring persons coming from EBOV affected areas. Moreover, people need to be advised to avoid travel to countries facing outbreak of EVD and to take necessary precautionary measures during their stay in such places. Monitoring the health of a person suspected to be ill or a carrier of EBOV for a minimum period of 21 days and seeking immediate medical care in cases where symptoms of EVD have been observed, is very important. In hospital settings, medical doctors, healthcare workers, and other persons who come in contact with persons suspected or treated for EBOV infection should wear protective clothing such as masks, gloves, gowns, and goggles, and should practice barrier nursing techniques that are important for prevention of the disease. The sample processing from EBOV-infected individuals should be done only in BSL-4 laboratories to prevent the spread of the virus. Climatic changes and the unusual variations in rainfall/dry season pattern may also change the activities of bats to a great extent, thereby leading to an increase in the cases of Ebola hemorrhagic fever and closely related Marburg fever virus infection among humans, gorillas, and chimpanzees, as well as the emergence or re-emergence of diseases being transmitted by them, including EBOV [57]. Accordingly, a check on the bat population, which is considered to be the reservoir host of these infections, has been advocated. However, in light of new evidence revealing that the spill over of Hendra viruses from the bat population was intermittent and probably increased due to shortage of food and pregnancy-related stress, it has been opined that culling and dispersing the fruit bat population would not work to bring down the cases of bat-borne diseases, including Ebola.

It is high time to work collectively for global preparedness against emerging infections, including Ebola, by constituting rapid response teams, involving trained human resource from veterinary, medical, and wildlife health streams; strengthening diagnostic testing facilities; boosting research and development activities in the developing and developed world; increasing public awareness; and motivating the masses for their active participation. To prevent Ebola cases in unaffected countries, strong and comprehensive national preparedness is a prerequisite that involves screening of passengers coming from Ebola-affected countries and creating awareness regarding the facts about Ebola that one cannot get Ebola through air, water, or food. Only informed and empowered communities can complement public health efforts to fight Ebola. 


\section{Vaccines}

No licensed human or animal vaccine is presently available for the prevention and control of the lethal EVD. Several experimental trials are underway in various parts of the world to find an efficient vaccine to prevent EBOV infection and spread [58]. EBOV glycoprotein (GP) is a crucial target for developing protective humoral immunity. Human monoclonal antibodies developed against the surface protein of EBOV raised hope for a safer vaccine [31]. A combined DNA vaccination and boost with ZEBOV GP-encoding adenoviral vectors resulted in the development of humoral and cellular immune responses in non-human primates such as cynomolgus macaques. The DNA vaccine has shown good protection in guinea pigs and mice. On challenge with the wild type, very pathogenic Mayinga 1976 strain of Ebola Zaire virus, none of the vaccinated animals showed clinical symptoms, and vthe irus was undetectable for more than six months [59]. A bivalent cAdVaxE (GPs/z) vaccine (adenovirus-based vaccine, cAdVax) has been reported to have been developed against the Sudan and Zaire Ebola viruses (ZEBOV and SEBOV), utilizing GP genes of SEBOV and ZEBOV, and its trial in mice showed $100 \%$ protection with efficiently inducted virus-specific antibodies as well as cell-mediated immunity [60]. In non-human primates, a single intramuscular injection of this vaccine induced both humoral and cellular immune responses. Shedding of vaccine vector was not noticed in monkeys, and none of the animals showed fever or other symptoms of illness after vaccination. A vaccine based on recombinant vesicular stomatitis virus (rVSV) expressing a single filovirus GP has been found to be promising in protecting nonhuman primates from Marburg virus and the three species of Ebola virus infection. Also, VSV-based vaccines have shown protection in cynomolgus macaques against Bundibugyo EBOV, with results indicating that complete protection requires incorporation of BEBOV GP or a prime-boost vaccine regime [61]. Also, the blended heterologous (SEBOV/ZEBOV) rVSV-based filovirus vaccine vectors, if used in prime-boost approach, can provide protection. Direct immunization of the respiratory tract with an intranasal vaccine by using replication-competent human parainfluenza virus type 3 (HPIV3) expressing the EBOV GP (HPIV3/EboGP) revealed immunogenic and protective responses against EBOV in a high-dose parenteral administration [62]. A cytomegalovirus (CMV)-based vaccine (MCMV/ZEBOV-NP ${ }_{\mathrm{CTL}}$ : murine $\mathrm{CMV}$ expressing a CD8 $\mathrm{T}$ cell epitope from EBOV nucleoprotein $[\mathrm{NP}]$ ) has been shown to provide longlasting EBOV protective immunity in mice with a single dose. This vaccine could have potent implications for vaccination in humans against EBOV as well as for formulating a disseminating vaccine for these highly lethal viruses in wild African great apes [63]. Vaccination strategy with EBOV-like particles (eVLPs) include EBOV nucleoprotein (NP), glycoprotein (GP), and the VP40 matrix protein. In non-human primates, it provided complete protection against challenge with lethal EBOV. Based on safety and efficacy, eVLPs have shown a way towards effective EBOV vaccine for human use. Reverse genetics has made it possible to develop a replication defective EBOV lacking the VP30 gene that is the transcriptional activator gene, which protected $100 \%$ of guinea pigs and mice challenged with lethal virus [64]. Presently, many efforts are being made to search for an effective and safe Ebola vaccine [65]. The WHO has announced that the two promising candidate vaccines (chimpanzee adenovirus vaccine and VSVbased vaccine) are currently undergoing phase III trials, which are expected to be released by the end of 2015 [59].

On an encouraging note, the scientific group working at University of Texas, USA, recently reported that a single dose of a breathable respiratory vaccine may provide long-term protection against the deadly EBOV. In this study, a non-injectable vaccine given in non-human primates resulted in the survival of $67 \%-100 \%$ of vaccinated animals after they were challenged with 1,000 plaque-forming units of ZEBOV at 150 days of immunization, compared to the $50 \%$ protection in primates when this vaccine was given via the intra-muscular route. Moreover, the aerosol method of immunization not only had ease of vaccine delivery but was also more economical than the injectable vaccine, which has a higher cost in terms of syringe distribution, needle safety, and disposal.

\section{Treatment}

Currently, there are no antiviral drugs that can fight against EBOV, and hence treatment is supportive only to sustain life. Intensive supportive care is required for patients who are severely ill. Analgesics to relieve pain and intravenous fluids to maintain osmotic balance are suggested. Earlier, several attempts were made to transfer the convalescent blood from diseased patients to healthy persons for a protective result; however, these were inadequate to prove that antibodies developed against EBOV had 
neutralizing power. Much research is underway to find a suitable and/or novel drug to treat and control the disease, and several promising candidates have been identified [66,67]. Estrogen receptor drugs such as clomiphene and toremifene (US Food and Drug Administration [FDA] approved), which are selective estrogen receptor modulators (SERMs) used for treating infertility, have been found to inhibit EVD progression in infected mice. Their anti-EBOV activity relies on the inhibition of virus entry after internalization and affects the triggering of fusion of Ebola viruses to host cells [68]. Recent report suggests that drugs like amiodarone, an ion channel blocker that is used to treat heart arrhythmias, could block the EBOV entry into cells in vitro [69]. On the basis of their bioavailability as well as history of use in human medicine, such drugs either alone or in combination with other suitable antiviral drugs have been identified as promising candidates for the treatment of EVD, especially in geographically remote locations.

Antisense technology forms the basis of other promising treatments [70]. Antisense refers to short DNA or RNA sequences, termed oligonucleotides, which are designed to be complementary to a specific gene sequence. The goal is to alter specific gene expression resulting from the binding of the antisense oligonucleotide to a unique gene sequence. Favipiravir (pyrazinecarboxamide derivative T-705), which proved effective for curing EBOV infection in a mouse model, is now at the final stages of trials. The mechanism of action is selective inhibition of viral RNA-dependent RNA polymerase. Favipiravir does not inhibit RNA or DNA synthesis in mammalian cells and is not toxic to them [71]. Other upcoming approaches to anti-EBOV therapy include use of RNA polymerase inhibitors to block viral nucleic acid synthesis, viral gene expression, or small interfering si-RNA nanoparticles to target specific viral proteins and inhibit viral protein production. A viral RNA polymerase inhibitor namely BCX4430 (an adenosine analogue) acts as a non-obligate RNA chain terminator, and when administered intramuscularly in rodents, it was found to be protective against EBOV infection even in the post-exposure phase [72,73]. Double-stranded RNA binding protein 76 (DRBP76), via its association with EBOV VP35, has been described to interact with viral proteins, with viral RNAs, and with the interferon-induced antiviral kinase PKR; it also inhibits EBOV polymerase function [74]. Small interfering RNA (siRNA) has been employed to silence disease-causing genes and has demonstrated utility in the inhibition of EBOV replication by targeting RNA polymerase L-protein, which has resulted in the development of a potential RNA interference-based therapy for ZEBOV infection. It has been suggested to be an effective post-exposure treatment regimen for EBOV-infected people [75]. Used as candidate antiviral drugs, both the siRNAs and advanced antisense therapeutics (phosphorodiamidate morpholino oligomers, PMO) targeting the Zaire Ebola virus (ZEBOV) RNA polymerase L-protein have been found to prevent EVD in non-human primates $[70,75]$. Very recently, Investigational New Drug (IND) applications have been approved by the US FDA, and phase I clinical trials have been initiated for two small-molecule therapeutics: anti-sense PMOs (AVI-6002, AVI-6003) and lipid nanoparticle (LNP)/siRNA (TKM-Ebola). LNP encapsulation provides an efficient delivery technology for the systemic delivery of RNAi triggers. However, the major drawback with such potential drug regimens is the requirement of multiple doses for achieving the proper therapeutic efficacy, which is not ideal with regard to patient compliance and outbreak scenarios [66]. The microRNA (mi-RNAs: hsa-miR1246, hsa-miR-320a, and hsa-miR-196b-5p) inhibitors have also been suggested to lower the cytotoxicity of Ebola virus glycoprotein in in vitro trials [76]. Nevertheless, more studies are needed before the final clearance and launch of any safe and efficacious antiviral drug in the global market, as considerable differences exist in the defence systems of human and small animal models, and therefore, the results of animal experimentations cannot be directly extrapolated for human beings.

Under compelling reasons to save the lives of sick persons, especially the health personnel affected during 2014 Ebola epidemic, passive transfer of neutralizing antibodies was proposed to be the most promising and viable options among the currently available regimens for treating EVD [77], as humanized mouse antibodies known as ZMapp were found to be a promising cure in non-human primates $[78,79]$. Accordingly, the WHO on August 12, 2014, approved ZMapp, co-developed by Mapp BioPharmaceuticals (San Diego, USA) and Defyrus Inc. (Toronto, Canada) for the treatment of EBOV infection. ZMapp is a combination (cocktail) of three humanized monoclonal antibodies (mAbs) against the EBOV GP protein [79]. The WHO approved the use of convalescent serum and whole blood products for treating newly affected patients so as to control the spread of EVD outbreaks [59]. Recently, the weak spots in EBOV structure that are targeted by the 
antibodies in ZMapp have been identified, and the findings may be helpful in developing an effective drug to treat Ebola-infected patients. Nevertheless, ZMapps has limited options for immediate mass use, as a huge gap exists in its demand and supply. Of late, plant-based production of ZMapps has been suggested as a way forward to ensure bulk production of ZMapps required for treating large number of Ebolal-infected patients, since mAbs expressed in the glycomodified Nicothiana benthamiana plants showed superior antiEBOV efficacy in animal models compared to those produced in Chinese hamster ovary (CHO) cells [79].

\section{Conclusions and future perspectives}

The ongoing yearlong outbreaks of EVD are the classic examples of emerging or re-emerging zoonoses, which, on account of their exceptional infectious or contagious nature, quickly assumed the regional, national, and occasionally pandemic proportions. Furthermore, such episodes encourage us to remain prepared for combating such deadly pathogens through multidisciplinary and collaborative approaches involving health and scientific communities worldwide. To culminate the ongoing international public health emergency declared in the form of EVD, there is an urgency to develop rapid and confirmatory diagnostic approaches, and an urgency to consolidate surveillance, monitoring, tracking, and networking systems. The countries need to adopt appropriate and recommended strategies, be equipped with the containment clinical units and BSL-4 facilities necessary to contain the EVD fatal outbreaks, and follow appropriate preparedness standards to prevent the spread of Ebola and anxiety about the EVD outbreak. A prophylactic, safe, and effective vaccine based on new-generation technologies is the required to counter EVD. Equally important remains the quest for a safe and effective drug along with various alternative and complementary therapeutic regimens for effectively curing EVD patients and safeguarding mankind from the threat of this highly lethal virus. In the era of the One World - One Medicine - One Health concept for protecting human and animal health, and the safeguarding of the environment at a global level, an ultimate aim of formulating appropriate disease prevention and control strategies needs to be focused in the right directions to counter the menace of EVD.

\section{Acknowledgements}

The authors thank and acknowledge their institute (Indian Veterinary Research Institute, Izatnagar) and Indian Council of Agricultural Research, New Delhi.

\section{References}

1. Bausch DG, Schwarz L (2014) Outbreak of Ebola Virus Disease in Guinea: Where Ecology Meets Economy. PLoS Negl Trop Dis 8: e3056.

2. Muyembe-Tamfum JJ, Mulangu S, Masumu J, Kayembe JM, Kemp A, Paweska JT (2012) Ebola virus outbreaks in Africa: past and present. Onderstepoort J Vet Res 79: 451.

3. Bellizzi S (2014) The current Ebola outbreak: old and new contexts. J Infect Dev Ctries 8: 1378-1380. doi:10.3855/jidc.6142.

4. Weingartl HM, Nfon C, Kobinger G (2013) Review of Ebola virus infections in domestic animals. Dev Biol (Basel) 135: 211-218.

5. Feldmann F1, Feldmann H (2014) Ebola: facing a new transboundary animal disease? Dev Biol (Basel) 135: 201209.

6. Centers for Disease Control and Prevention (2015) Ebola Outbreak in West Africa - Case Counts. As of April 11, 2015. Updated April 13, 2015. Available: http://www.cdc.gov/vhf/ebola/outbreaks/2014-westafrica/case-counts.html. Accessed on April 15, 2015

7. Kuhn JH, Becker S, Ebihara H, Geisbert TW, Johnson KM, Kawaoka Y, Lipkin WI, Negredo AI, Netesov SV, Nichol ST, Palacios G, Peters CJ, Tenorio A, Volchkov VE, Jahrling PB (2010) Proposal for a revised taxonomy of the family Filoviridae: Classification, names of taxa and viruses, and virus abbreviations. Arch Virol 155: 2083-2103.

8. Gatherer D (2014) The 2014 Ebola virus disease outbreak in West Africa. J Gen Virol 95: 1619-1624.

9. Bausch DG, Schwarz L (2014) Outbreak of Ebola Virus Disease in Guinea: Where Ecology Meets Economy. PLoS Negl Trop Dis 8: e3056.

10. Toit AD (2014) Ebola virus in West Africa. Nature Rev Microbiol 12: 312.

11. Baize S, Pannetier D, Oestereich L, Rieger T, Koivogui L, Magassouba N, Soropogui B, Sow MS, Keita S, DeClerck H, Tiffany A, Dominguez G, Loua M, Traore A, Kolie M, Malano ER, Heleze E, Bocquin A, Mely S, Raoul H, Caro V, Cadar D, Gabriel M, Pahlmann M, Tappe D, SchmidtChanasit J, Impouma B, Diallo AK, Formenty P, Van Herp M, Gunther S (2014) Emergence of Zaire Ebola virus disease in Guinea - Preliminary report. N Engl J Med 371: 14181425.

12. Feldmann H, Geisbert TW (2011) Ebola haemorrhagic fever. Lancet 377: 849-862.

13. Suzuki Y, Gojobori T (1997) The origin and evolution of Ebola and Marburg viruses. Mol Biol Evol 14: 800-806.

14. Taylor DJ, Dittmar K, Ballinger MJ, Bruenn JA (2011) Evolutionary maintenance of filovirus-like genes in bat genomes. BMC Evol Biol 11: 336.

15. Olival KJ, Islam A, Yu M, Anthony SJ, Epstein JH, Khan SA, Khan SU, Crameri G, Wang LF, Lipkin WI, Luby SP, Daszak P (2013) Ebola virus antibodies in fruit bats, Bangladesh. Emerg Infect Dis 19: 270.

16. Casillas AM, Nyamathi AM, Sosa A, Wilder CL, Sands H (2003) A current review of Ebola virus: pathogenesis, clinical 
presentation, and diagnostic assessment. Biol Res Nurs 4: $268-275$.

17. Geisbert TW, Geisbert JB, Leung A, Daddario-DiCaprio KM, Hensley LE, Grolla A, Feldmann H (2009) Singleinjection vaccine protects nonhuman primates against infection with Marburg virus and three species of Ebola virus. J Virol 83: 7296-7304.

18. Muyembe-Tamfum JJ, Mulangu S, Masumu J, Kayembe JM, Kemp A, Paweska JT (2012) Ebola virus outbreaks in Africa: past and present. Onderstepoort J Vet Res 79: 451.

19. Tambo E, Ugwu EC, Ngogang JY (2014) Need of surveillance response systems to combat Ebola outbreaks and other emerging infectious diseases in African countries. Infect Dis Pov 3: 29.

20. Gatherer D (2014) The 2014 Ebola virus disease outbreak in West Africa. J Gen Virol 95: 1619-1624.

21. Zhang L, Wang $\mathrm{H}$ (2014) Forty years of the war against Ebola. J Zhejiang Univ Sci B 15: 761-765.

22. Johnson KM (1978) Ebola haemorrhagic fever in Zaire, 1976. Bull World Health Organ. 56: 271-293.

23. Pres B (1978) The epidemic of Ebola haemorrhagic fever in Sudan and Zaire, 1976: introductory note. Bull World Health Organ. 56: 245 .

24. Taniguchi S, Watanabe S, Masangkay JS, Omatsu T, Ikegami $\mathrm{T}$, Alviola P, Ueda N, Iha K, Fujii H, Ishii Y, Mizutani T, Fukushi S, Saijo M, Kurane I, Kyuwa S, Akashi H, Yoshikawa Y, Morikawa S (2011) Reston ebolavirus antibodies in bats, the Philippines. Emerg Infect Dis 17: 15591560.

25. Leroy EM, Rouquet $\mathrm{P}$, Formenty $\mathrm{P}$, Souquière $\mathrm{S}$, Kilbourne A, Froment JM, Bermejo M, Smit S, Karesh W, Swanepoel R, Zaki SR, Rollin PE (2004) Multiple Ebola virus transmission events and rapid decline of central African wildlife. Science 303: 387-390.

26. Nunes-Alves C (2014) Ebola update. Nat Rev Microbiol 2: 656.

27. Allela L, Boury O, Pouillot R, Délicat A, Yab P, Kumulungui B, Rouquet P, Gonzalez JP, Leroy EM (2005) Ebola virus antibody prevalence in dogs and human risk. Emerg Infect Dis 11: 385-390.

28. Osterholm MT, Moore KA, Kelley NS, Brosseau LM, Wong G, Murphy FA, Peters CJ, LeDuc JW, Russell PK, Van Herp M, Kapetshi J, Muyembe J-JT, Ilunga BK, Strong JE, Grolla A, Wolz A, Kargbo B, Kargbo DK, Formenty P, Sanders DA, Kobinger GP (2015) Transmission of Ebola viruses: what we know and what we do not know. MBio 6: e00137.

29. Leroy E, Epelboin A, Mondonge V, Pourrut X, Gonzalez JP, Muyembe-Tamfum JJ, Formenty P (2009) Human Ebola outbreak resulting from direct exposure to fruit bats in Luebo, Democratic Republic of Congo, 2007. Vector Borne Zoonotic Dis 9: 723-728.

30. Pigott DM, Golding N, Mylne A, Huang Z, Henry AJ, Weiss DJ, Brady OJ, Kraemer MU, Smith DL, Moyes CL, Bhatt S, Gething PW, Horby PW, Bogoch II, Brownstein JS, Mekaru SR, Tatem AJ, Khan K, Hay SI (2014) Mapping the zoonotic niche of Ebola virus disease in Africa. Elife 7: e04395.

31. Nyamathi AM, Fahey JL, Sands H, Casillas AM (2003) Ebola virus: immune mechanisms of protection and vaccine development. Biol Res Nurs 4: 276-281.

32. Geisbert T, Hensley L, Larsen T, Young H, Reed D, Geisbert J, Scott D, Kagan E, Jahrling P, Davis K (2003) Pathogenesis of Ebola Hemorrhagic Fever in Cynomolgus Macaques. American J Pathol 163: 2347-2370.

33. Wyers M, Formenty P, Cherel Y, Guigand L, Fernandez B, Boesch C, Le Guenno B (1999) Histopathological and immunohistochemical studies of lesions associated with Ebola virus in a naturally infected chimpanzee. J Infect Dis 179: S54-S59.

34. Muhlberger E, Weik M, Volchkov VE, Klenk HD, Becker S (1999) Comparison of the transcription and replication strategies of Marburg virus and Ebola virus by using artificial replication systems. J Virol 73: 2333-2342.

35. Basler CF, Mikulasova A, Martinez-Sobrido L, Paragas J, Muhlberger E, Bray M, Klenk, HD, Palese P, Garcia-Sastre A (2003) The ebolavirus VP35 protein inhibits activation of interferon regulatory factor 3. J Virol 77: 7945-7956.

36. Basler CF, Wang X, Muhlberger E, Volchkov V, Paragas J, Klenk HD, Garcia-Sastre A, Palese P (2000) The Ebola virus VP35 protein functions as a type I IFN antagonist. Proc Natl Acad Sci U S A 97: 12289-12294.

37. Wong G, Kobinger GP, Qiu X (2014) Characterization of host immune responses in Ebola virus infections. Expert Rev Clin Immunol 10: 781-790.

38. Harty RN, Brown ME, Wang G, Huibregtse J, Hayes FP (2000) A PPxY motif within the VP40 protein of Ebola virus interacts physically and functionally with a ubiquitin ligase: implications for filovirus budding. Proc Natl Acad Sci U S A 97: 13871-13876.

39. Jasenosky LD, Neumann G, Lukashevich I, Kawaoka Y (2001) Ebola virus VP40-induced particle formation and association with the lipid bilayer. J Virol 75: 5205-5214.

40. Noda T, Sagara H, Suzuki E, Takada A, Kida H, Kawaoka Y (2002) Ebola virus VP40 drives the formation of virus-like filamentous particles along with GP. J Virol 76: 4855-4865.

41. Takada A, Kawaoka Y (2001) The pathogenesis of Ebola hemorrhagic fever. Trends Microbiol 9: 506-511.

42. Shi M, Shen YQ (2013) Research progress of the molecule mechanisms of Ebola virus infection of cells. Bing Du Xue Bao 29: 71-75.

43. Feldmann H, Bugany H, Mahner F, Klenk HD, Drenckhahn D, Schnittler HJ (1996) Filovirus-induced endothelial leakage triggered by infected monocytes/macrophages. J Virol 70: 2208-2214.

44. Villinger F, Rollin PE, Brar SS, Chikkala NF, Winter J, Sundstrom J, Zaki SR, Swanepoel R, Ansari A, Peters CJ (1999) Markedly elevated levels of interferon (IFN)-gamma, IFN-alpha, interleukin (IL)-2, IL-10, and tumor necrosis factor-alpha associated with fatal Ebola virus infection. J Infect Dis 179: S188-S191.

45. Ksiazek TG, West CP, Rollin PE, Jahrling PB, Peters CJ (1999) ELISA for the detection of antibodies to Ebola viruses. J Infect Dis 179: S192-S198.

46. Hoenen T, Groseth A, Falzarano D, Feldmann H (2006) Ebola virus: unravelling pathogenesis to combat a deadly disease. Trends Mol Med 12: 206-215.

47. Okeke IN, Manning RS, Pfeiffer T (2014) Diagnostic schemes for reducing epidemic size of african viral hemorrhagic fever outbreaks. J Infect Dev Ctries 8: 11481159. doi:10.3855/jidc.4636.

48. Shrivastava SR, Shrivastava PS, Ramasamy J (2015) Ebola disease: An international public health emergency. Asian Pacific J Trop Dis 5: 253-262.

49. Drosten C, Gottig S, Schilling S, Asper M, Panning M, Schmitz H, Gunther S(2002) Rapid detection and 
quantification of RNA of Ebola and Marburg viruses, Lassa virus, Crimean-Congo hemorrhagic fever virus, Rift Valley fever virus, dengue virus, and yellow fever virus by real-time reverse transcription-PCR. J Clin Microbiol 40: 2323-2330.

50. Towner JS, Rollin PE, Bausch DG, Sanchez A, Crary SM, Vincent M, Lee WF, Spiropoulou CF, Ksiazek TG, Lukwiya M, Kaducu F, Downing R, Nichol ST (2004) Rapid diagnosis of Ebola hemorrhagic fever by reverse transcription-PCR in an outbreak setting and assessment of patient viral load as a predictor of outcome. J Virol 78: 4330-4341.

51. Mishra B (2014) The threat of Ebola: An update. Indian J Med Microbiol 32: 364-370.

52. Liu Y, Shi ZX, Ma YK, Wang HT, Wang ZY, Shao DH, Wei JC, Wang SH, Li BB, Wang SM, Liu XH, Ma ZY (2012) Development of SYBR Green I real-time RT-PCR for the detection of Ebola virus. Bing Du Xue Bao 28: 567-571.

53. Huang Y, Wei H, Wang Y, Shi Z, Raoul H, Yuan Z (2012) Rapid detection of filoviruses by real-time TaqMan polymerase chain reaction assays. Virol Sin 27: 273-277.

54. Yang Y, Bai L, Hu KX, Yang ZH, Hu JP, Wang J (2012) Multiplex real-time PCR method for rapid detection of Marburg virus and Ebola virus. Zhonghua Shi Yan He Lin Chuang Bing Du Xue Za Zhi 26: 313-315.

55. Kurosaki Y, Takada A, Ebihara H, Grolla A, Kamoc N, Feldmann H, Kawaoka Y, Yasuda J (2007) Rapid and simple detection of Ebola virus by reverse transcription-loopmediated isothermal amplification. J Virol Methods 141: 7883.

56. Baker A (2014) The race to diagnose. In Time Magazine. Cape Town, USA. 28-29.

57. Dhama K, Tiwari R, Chakraborty S, Kumar A, Karikalan M, Singh R, Rai RB (2013) Global warming and emerging infectious diseases of animals and humans: current scenario, challenges, solutions and future perspectives - a review. Int $\mathbf{J}$ Curr Res 5: 1942-1958.

58. Geisbert TW, Jahrling PB (2003) Towards a vaccine against Ebola virus. Expert Rev Vaccines 2: 777-789.

59. Gulland A (2014) First Ebola treatment is approved by WHO. British Med J 349: g5539.

60. Wang D, Raja NU, Trubey CM, Juompan LY, Luo M, Woraratanadharm J, Deitz SB, Yu H, Swain BM, Moore KM, Pratt WD, Hart MK, Dong JY (2006) Development of a cAdVax-based bivalent Ebola virus vaccine that induces immune responses against both the Sudan and Zaire species of Ebola virus. J Virol 80: 2738-2746.

61. Mire CE, Geisbert JB, Marzi A, Agans KN, Feldmann H, Geisbert TW (2013) Vesicular stomatitis virus-based vaccines protect nonhuman primates against Bundibugyo ebolavirus. PLoS Negl Trop Dis 7: e2600.

62. Yang L, Sanchez A, Ward JM, Murphy BR, Collins PL, Bukreyev A (2008) A paramyxovirus-vectored intranasal vaccine against Ebola virus is immunogenic in vectorimmune animals. Virology 377: 255-264.

63. Tsuda Y, Parkins CJ, Caposio P, Feldmann F, Botto S, Ball S, Messaoudi I, Cicin-Sain L, Feldmann H, Jarvis MA (2015) A cytomegalovirus-based vaccine provides long-lasting protection against lethal Ebola virus challenge after a single dose. Vaccine 33: 2261-2266.

64. Hoenen T, Groseth A, Feldmann H (2012) Current Ebola vaccines. Expert Opin Biol Ther 12: 859-872.

65. Cohen J (2014) Infectious Disease. Ebola vaccines racing forward at record pace. Science 345: 1228-1229.
66. Choi JH, Croyle MA (2013) Emerging targets and novel approaches to Ebola virus prophylaxis and treatment. BioDrugs 27: 565583.

67. Kilgore PE, Grabenstein JD, Salim AM, Rybak M (2015) Treatment of Ebola virus disease. Pharmacotherapy 35: 4353.

68. Johansen LM, Brannan JM, Delos SE, Shoemaker CJ, Stossel A, Lear C, Hoffstrom B.G., Dewald LE, Schornberg KL, Scully C, Lehár J, Hensley LE, White JM, Olinger GG (2013) FDA-approved selective estrogen receptor modulators inhibit Ebola virus infection. Sci Transl Med 5: 190 ra79.

69. Gehring G, Rohrmann K, Atenchong N, Mittler E, Becker S, Dahlmann F, Pöhlmann S, Vondran FW, David S, Manns MP, Ciesek S, von Hahn T (2014) The clinically approved drugs amiodarone, dronedarone and verapamil inhibit filovirus cell entry. J Antimicrob Chemother 69: 2123-2131.

70. Warren TK, Warfield KL, Wells J, Swenson DL, Donner KS, Van Tongeren SA, Garza NL, Dong L, Mourich DV, Crumley S, Nichols DK, Iversen PL, Bavari S (2010) Advanced antisense therapies for postexposure protection against lethal filovirus infections. Nat Med 16: 991-994.

71. Oestereich L, Ludtke A, Wurr S, Rieger T, Muñoz-Fontela C, Gunther S (2014) Successful treatment of advanced Ebola virus infection with T-705 (favipiravir) in a small animal model. Antiviral Res 105: 17-21.

72. Fauci AS (2014) Ebola-underscoring the global disparities in health care resources. The New Eng J Med 371: 1084-1086.

73. Warren TK, Wells J, Panchal RG, Stuthman KS, Garza NL, Van Tongeren SA, Dong L, Retterer CJ, Eaton BP, Pegoraro G, Honnold S, Bantia S, Kotian P, Chen X, Taubenheim BR, Welch LS, Minning DM, Babu YS, Sheridan WP, Bavari S (2014) Protection against filovirus diseases by a novel broadspectrum nucleoside analogue BCX4430. Nature 508: 402405.

74. Shabman RS, Leung DW, Johnson J, Glennon N, Gulcicek EE, Stone KL, Leung L, Hensley L, Amarasinghe GK, Basler CF (2011) DRBP76 associates with Ebola virus VP35 and suppresses viral polymerase function. J Infect Dis 204: S911S918.

75. Geisbert TW, Lee AC, Robbins M, Geisbert JB, Honko AN, Sood V, Johnson JC, de Jong S, Tavakoli I, Judge A, Hensley LE, Maclachlan I (2010) Post exposure protection of nonhuman primates against a lethal Ebola virus challenge with RNA interference: A proof-of-concept study. Lancet 375: 1896-1905.

76. Sheng M, Zhong Y, Chen Y, Du J, Ju X, Zhao C, Zhang G, Zhang L, Liu K, Yang N, Xie P, Li D, Zhang MQ, Jiang C (2014) Hsa-miR-1246, hsa-miR-320a and hsa-miR-196b-5p inhibitors can reduce the cytotoxicity of Ebola virus glycoprotein in vitro. Sci China Life Sci 57: 959-972.

77. Saphire EO (2013) An update on the use of antibodies against the filoviruses. Immunotherapy 5: 1221-1233.

78. Wong G, Qiu X, Olinger GG, Kobinger GP (2014) Postexposure therapy of filovirus infections. Trends Microbiol 22: 456.

79. Zhang Y, Li D, Jin X, Huang Z (2014) Fighting Ebola with ZMapp: spotlight on plant-made antibody. Sci China Life Sci 57: 987-988. 


\section{Corresponding author}

Dr. Yashpal Singh Malik

ICAR-National Fellow,

Indian Veterinary Research Institute,

Izatnagar 243122, Bareilly, Uttar Pradesh, India

Phone: +91-5812302777

Fax: +91-5812301757

Email: malikyps@ivri.res.in

Conflict of interests: No conflict of interests is declared. 